\title{
The Physician's Role in Political Advocacy
}

Mitchell Rock ${ }^{1}$

${ }^{1}$ Georgetown University School of Medicine

Keywords: advocacy, politics, policy, bioethics

https://doi.org/10.52504/001c.21357

\section{Georgetown Medical Review}

Vol. 5, Issue 1, 2021

In 2018, the National Rifle Association (NRA) tweeted "Someone should tell self-important anti-gun doctors to stay in their lane." The result was the This Is Our Lane movement, where physicians and other health professionals shared stories and photographs regarding their experiences treating victims of gun violence. ${ }^{1}$ Two years later, the New England Journal of Medicine (NEJM) published an editorial entitled "Dying in a Leadership Vacuum". In this editorial, the famed medical journal took the unprecedented step of condemning the country's leadership in response to the failed response to the COVID-19 pandemic. $^{2}$ These events highlight an ideological divide in the common understanding of the role of physicians. The NRA posited that doctors have no role in advocacy, at least on the issue of gun violence. The response by some physicians suggests that they disagree, and they believe it is part of their role in society to address issues such as this one. The response of the NEJM to the COVID-19 pandemic suggests that they too feel as though medical providers have a role in advocacy, even when it is overtly political. The result is an important question regarding the role of physicians and other health professionals - what is the role of the physician in political advocacy? I argue that while physicians must balance their responsibilities to individual patients and to society as a whole, they should act within their rights as moral agents to address the public policies that shape human health and well-being.

In addressing this question, we are asking what the role of the physician is and what it should be. The primary role of the physician should indeed be as a healer of individuals. Patients who enter a relationship with a physician expect that this role, and thus their wellbeing, will be the primary concern of the physician. However, it has been argued that the physician is also a servant of society and must use medicine as a societal good to treat population level concerns. ${ }^{3}$ Medicine holds a social contract with society that affords its practitioners with special privileges. ${ }^{4}$ These privileges include substantial financial benefit, prestige, and entrustment with sensitive information. This social contract requires a benefit to society in exchange for these privileges, namely service to society as a whole and placing society's concerns before its own. ${ }^{5}$ 
The physician can uphold the social contract with society by addressing the social and political determinants of health, which physicians have the unique knowledge and expertise to understand due to their intimate encounters with the human experience of illness. ${ }^{6}$ While there are many ways the physician could accomplish the goal of addressing these determinants of health, one avenue can certainly involve political advocacy because public policy on every level of government has far-reaching implications on these determinants. As examples, the government directly decides who can access government health insurance, and it also indirectly impacts issues such the obesity epidemic by shaping the affordability of healthy food. Thus, advocacy is clearly one method of shaping determinants of health, since so many of the social conditions that allow illness to prosper arise from policy failures and social ills that require collective action through government.

The conflict that emerges between the physician's roles as an individual healer and a servant to the larger society is encapsulated in the question of whether engaging in political advocacy may lead patients to view physicians as partisan, and thus biased and potentially untrustworthy. If this occurs, it could diminish the trust necessary in the physician-patient relationship. Without this trust, patients may not heed the advice of the physician, or may not seek out the service of the physician as readily as they otherwise would have. Conversely, other patients could see physician advocacy as a demonstration of the care their physicians have for them. This could result in increased trust, and thus an improved physician-patient relationship.

Additionally, despite concerns that anything related to politics can be divisive and lead to distrust from patients, the physician is a moral agent and has a right to follow his or her conscience when doing so does not cause harm to others. Some, such as bioethicist Dr. Edmund Pellegrino, have argued that part of the physician's conscience is their perception of what constitutes good medicine based on their own notions of personal and professional morality. ${ }^{7}$ If the physician comes to believe that advocacy is necessary to meet the requirements of morally righteous medicine as defined by their conscience, they have a right to engage in that activity.

Furthermore, the wellbeing of a physician's patients may require changes on a policy level. Healing an individual may often be beyond the scope of the physician if they are limited to only utilizing clinical skills and treatments. Instead, healing may often require changes in policy and social situations. For example, if a patient cannot afford a necessary medication, it is in the best interest of that patient for the physician to engage in advocacy that could result in lower drug prices. Thus, advocacy does not merely fall into the role of the physician as a social servant, but it can also support the physician in accomplishing their primary objective to improve the wellness of individual patients. 
Nevertheless, there is still a trade off with one crucial resource - the time of the physician. If physicians are ethically bound to a social responsibility to engage in advocacy, they will have less time with individual patients. This concern may be negligible if we lived in a society with a plethora of health professionals; however, the growing shortage of physicians makes this issue even more salient. Despite this concern, this tradeoff already occurs in many other contexts. Many physicians spend great portions of their occupational time teaching future generations of doctors and conducting research to improve the care patients receive. These activities provide great benefit to current and future patients and are thus allowed to be prioritized in some capacity. Addressing social ills through methods such as advocacy should be considered similarly since doing so also has the potential to provide great benefit to current and future patients. This trade-off must be carefully balanced, but so long as when the physician treats patients, they do not let their advocacy efforts interfere with the care of that patient, it is a trade-off they should be allowed to make in their best judgement.

Through the arguments laid out above, it is clear that the physician should strive to engage in political advocacy. Political advocacy likely does more to benefit than harm the role of the physician as an individual healer and fulfils the social responsibility of the physician. Moreover, the physician has a level of respect in society, a base of knowledge, and a unique set of experiences through their profession that may make their advocacy particularly effective. While the physician should engage in advocacy, that does not mount to an obligation for the physician. This goes back to the right of conscience medicine. Many physicians may not deem advocacy a part of the moral requirement of medicine, and that is their right. Further, not every physician will believe they have an understanding of policy or politics that allows them to be an effective advocate. These physicians should not be mandated to engage in advocacy despite these qualms. Instead, these physicians must find another way to meet their professional requirements to the social contract.

Physicians should utilize the full breadth of their status within their communities to help steer the collective body politic towards a more just society that promotes the health and well-being of all of its members. This position has been adopted by the American Medical Association in their Declaration of Professional Responsibility. ${ }^{8}$ This body has declared that humanity is the patient of the physician, and that physicians must commit to advocate for political changes that contribute to human well-being. ${ }^{8}$ However, advocacy should not be an obligation, but one of many avenues a physician can take to fulfil their social responsibility. In looking back upon the examples from the introduction, it becomes clear that the NRA was wrong. The NEJM and the This Is Our Lane movement were acting well within the role of the physician because advocating for the improvement of human well-being is very much so a lane in which physicians belong. 


\section{REFERENCES}

1. Wamsley L. After NRA Mocks Doctors, Physicians Reply: 'This Is Our Lane'

[Internet].https://www.npr.org/2018/11/11/666762890/after-nra-mocks-doctors-physiciansreply-this-is-our-lane. Published November 11, 2018.

2. Editors. Dying in a Leadership Vacuum. N Engl J Med. 2020;383(15):1479-1480. doi:10.1056/ nejme2029812

3. Pellegrino ED. The Moral Foundations of the Patient-Physician Relationship: The Essence of Medical Ethics in Military Medical Ethics. In: Beam TE, Sparacino L, eds. Military Medical Ethics. Vol 1. Office of the Surgeon General, US Army; 2003:6-21.

4. Cruess R, Cruess S. Updating the Hippocratic Oath to include medicine's social contract. Med Educ. 2014;48(1):95-100. doi:10.1111/medu.12277

5. Dharamsi S, Ho A, Spadafora SM, Woollard R. The Physician as Health Advocate: Translating the Quest for Social Responsibility Into Medical Education and Practice. Acad Med.

2011;86(9):1108-1113. doi:10.1097/acm.0b013e318226b43b

6. Coulehan J, Williams PC, McCrary SV, Belling C. The Best Lack All Conviction: Biomedical Ethics, Professionalism, and Social Responsibility. Camb Q Healthc Ethics. 2003;12(1):21-38.

doi:10.1017/s0963180103121044

7. Pellegrino ED. The Physician's Conscience, Conscience Clauses, and Religious Belief: A Catholic Perspective. Fordham Urban Law Jrnl. 2002;1:221-244.

8. AMA. A Declaration of Professional Responsibility. AMA. 2001; [Reaffirmed 2007; reaffirmed 2017]. Report No.: H-140.900. 